\title{
El estilo Fosburi, la imaginación, la laparoscopia y... Actas Urológicas Españolas
}

\author{
Ruiz Cerdá JL.
}

Servicio de Urología. Hospital La Fe. Valencia.

Actas Urol Esp 2006; 30 (5): 440-442

$\mathrm{E}^{\mathrm{s}}$ objetivo en el salto de altura es sobrepasar, sin derribar, una barra horizontal (listón) que se encuentra suspendida entre dos soportes verticales separados unos 4 metros. Mucho ha cambiado la técnica desde que en los inicios se saltara un listón con los pies juntos y sin carrera, o se utilizara la "tijera" que inventó el francés Lewden. El saltador tomaba carrera y afrontaba el listón haciendo una especie de tijera con sus piernas, pasando primero una pierna y después la otra. Con esta técnica se llegó a saltar hasta 1,97 metros, lo cual no es nada desdeñable.

La siguiente revolución la introdujo George Horine y se llamó "western roll". Era una especie de rodillo, ya que el cuerpo volteaba sobre el listón, pero se hacía de espaldas. Horine fue el primer atleta que flanqueó los dos metros. El método de Horine se fue perfeccionando y se cambió la forma de atacar el listón, de tal forma que el cuerpo se colocaba a horcajadas sobre él, de ahí el nombre de "rodillo ventral". El soviético Valeri Brumel fue el máximo exponente del rodillo ventral y llegó a saltar 2,28 metros. Sin embargo, en los Juegos Olímpicos de México'68 apareció un casi desconocido saltador norteamericano que pasaba el listón con un muy peculiar estilo. Su nombre: Dick Fosbury. En principio la nueva forma de saltar pareció rudimentaria e imperfecta, pero los resultados fueron avasalladores. La técnica consistía en tomar una rápida y potente carrera corta, describiendo un semicírculo, para en el momento de batir el salto, hacer una rotación del cuerpo, mientras éste se elevaba, pasando primero la cabeza y el cuerpo sobre el listón, de espaldas, para después realizar un nuevo esfuerzo y elevar las piernas juntas para no tocar el listón. Hubo unos años en los que nadie domi- nó de manera absoluta la prueba, hasta que poco tiempo después todos los atletas adoptaron el nuevo estilo. En la actualidad el récord absoluto lo posee Javier Sotomayor, que saltó el 27 de julio de 1993 en Salamanca, nada más y nada menos que 2,45 metros con el estilo Fosbury. Esta interesante historia atlética sobre la técnica del salto de altura pone de manifiesto como la evolución técnica es esencial para conseguir mejoras. Sin embargo, hay que tener presente que, detrás de cada nueva técnica hay todo un proceso de creación imaginativa previo dentro de la mente humana. Como dijo Einstein, para avanzar "la imaginación es más importante que el saber".

Es indudable que sin imaginación la laparoscopia no se hubiese desarrollado. Su irrupción en nuestra especialidad ha supuesto que los urólogos, tarde o temprano, si miran hacia delante, van a tener que tomar la decisión profesional de aprenderla. Principalmente, porque han tomado conciencia de que, en si misma, como el estilo Fosbury, no supone un cambio de objetivo (sobrepasar el listón), sino un nuevo abordaje que requiere cambios conceptuales, técnicos y adquisición de habilidades para, por ejemplo, extirpar un riñón o la próstata con la misma radicalidad oncológica que con cirugía abierta.

El aprendizaje de la técnica laparoscopia requiere de un método sistematizado por pasos. El objetivo de este monográfico es ayudar a los urólogos (aunque es idéntico para cualquier especialidad quirúrgica) a conocer cada una de las etapas que debe llevar a cabo para iniciarse en la laparoscopia. La idea principal ha sido combinar la descripción de cada uno de los procedimientos, pues son el resultado último de todo el proceso, con la descripción del método y la sistemática que se debe seguir para lograr dominar la 
Tabla 1

Artículos publicados en Actas Urológicas Españolas dedicados a la laparoscopia urológica según tipo de artículo, patología técnica y temática

\begin{tabular}{|c|c|c|c|c|c|c|}
\hline Autor* & Año & $\begin{array}{l}\text { Referencia } \\
\text { Actas Urol Esp }\end{array}$ & Tipo Artículo & Patologia & Técnica & Tema \\
\hline \multirow[t]{2}{*}{ Aguilera Bazan A et al. } & 2005 & $29(7): 657-661$ & Original & Retroperitoneal & $\begin{array}{l}\text { Nefrectomía simple, radical, } \\
\text { pieloplastia }\end{array}$ & Tratamiento \\
\hline & 2004 & $28(1): 27-31$ & Experimental & Trasplante renal & Suturas vasculares & Técnica \\
\hline Blas Marin M et al. & 1997 & 21(9):874-89 & Original & Cáncer próstata & Linfadenectomía & Estadiaje \\
\hline Burgos FJ et al. & 2002 & 26(10):731 & Revisión & Trasplante renal & Extracción donante vivo & Técnica \\
\hline Cerqueira $\mathrm{M}$ et al. & 2004 & $28(7): 535-8$ & Nota clínica & Siringocele glándulas Cowper & Apertura & Tratamiento \\
\hline \multirow[t]{3}{*}{ Chicharro Molero JA et al. } & 1996 & $20(10): 920-4$ & Original & Incontinencia urinaria & Colposuspensión extraperitoneal & Tratamiento \\
\hline & 1993 & 17(6):388-91 & Nota clínica & Riñón doble & Exéresis & Tratamiento \\
\hline & 1993 & $17(6): 357-60$ & Original & Cáncer próstata & Linfadenectomía & Estadiaje \\
\hline Escribano Patino G et al. & 1996 & 20(3):296-301 & Nota clínica & Trasplante renal & Nefrectomía bilateral & Tratamiento \\
\hline \multirow[t]{2}{*}{ Estebánez Zarranz J et al. } & 2003 & 27(5):370-8 & Original & Cáncer próstata & Prostatectomía radical & Tratamiento \\
\hline & 1999 & 23(8):732-5 & Nota clínica & Ptosis renal & Nefropexia & Tratamiento \\
\hline \multirow[t]{5}{*}{ Farina Pérez LA et al. } & 2006 & $30(2): 218-22$ & Nota clínica & Litiasis ureteral & Ureterolitotomía & Tratamiento \\
\hline & 2005 & 29(4):434-5 & Nota clínica & Fibrosis retroperitoneal & Ureterolisis & Tratamiento \\
\hline & 2004 & $28(8): 620-3$ & Nota clínica & Litiasis renal & Pielolitotomía & Tratamiento \\
\hline & 2004 & $28(1): 54-6$ & Nota clínica & Cáncer renal & Nefrectomía parcial & Complicación \\
\hline & 2003 & $27(2): 168-9$ & Nota clínica & Todas & Cierre puertos & Técnica \\
\hline Foncillas $\mathrm{J}$ et al. & 1993 & $17(3): 210-1$ & Nota clínica & Divertículo vesical & Diverticulectomía & Tratamiento \\
\hline Franco Miranda E et al. & 1997 & $21(7): 712-3$ & Original & Vesical & Drenaje con trocares & Técnica \\
\hline Garcia Garcia MA et al. & 2002 & $26(4): 286-9$ & Nota clínica & Enfermedad de Hodgkin & Linfadenectomía & $\begin{array}{l}\text { Tratamiento- } \\
\text { diagnóstico }\end{array}$ \\
\hline Hernández Fernández C et al. & 1994 & 18(5):619-22 & Nota clínica-revisión & Renal & Nefrectomía retroperitoneal & Tratamiento \\
\hline Laguna $\mathrm{P}$ et al. & 2005 & 29(9):860-8 & Original-revisión & Cáncer renal & Crioablación laparoscópica & Tratamiento \\
\hline Lledó García E et al. & 1996 & $20(7): 648-54$ & Revisión & Trasplante renal - Linfocele & Drenaje & Tratamiento \\
\hline Llorente Abarca $\mathrm{C}$ et al. & 2005 & $29(4): 349-54$ & Original & Cáncer próstata & Prostatectomía radical & Docencia \\
\hline Luque Mialdea R et al. & 1999 & 23(6):483-8 & Original & Urologia pediátrica & Varias & Indicaciones \\
\hline Novas Castro $\mathrm{S}$ et al. & 2005 & $29(3): 241-3$ & Editorial & Todas & Todas & Docencia \\
\hline Páramo PG et al. & 1985 & $9(4): 331-40$ & Revisión & Testículo intraabdominal & Laparoscopia diagnóstica & Diagnóstico \\
\hline Pascual Piedrola JI et al. & 2005 & $29(10): 927-33$ & Original & Cáncer próstata & Prostatectomía radical & Docencia \\
\hline \multirow[t]{5}{*}{ Rioja Sanz C et al. } & 1994 & 18 Suppl:468-77 & Revisión & Varias & Varias & Indicaciones \\
\hline & 1992 & $16(7): 544-8$ & Nota clínica & Renal & Nefrectomía & Tratamiento \\
\hline & 1992 & $16(4): 280-3$ & Original & Litiasis ureteral & Ureterolitotomía & Tratamiento \\
\hline & 1991 & $15(6): 515-7$ & Original & Cáncer próstata & Linfadenectomía & Estadiaje \\
\hline & 1990 & 14(6):466 & Editorial & Varias & Varias & Indicaciones \\
\hline Rioja Sanz LA & 1992 & $16(7): 528$ & Editorial & Varias & Varias & $\begin{array}{l}\text { Indicaciones- } \\
\text { tratamiento }\end{array}$ \\
\hline \multirow[t]{3}{*}{ Valdivia Uría JG } & 2002 & 26(8):552-62 & Revisión & Todas & Todas & Técnica \\
\hline & 1994 & 18 Suppl:346-50 & Original & Litiasis riñón herradura & Pielolitotomía & Tratamiento \\
\hline & 1992 & 16(2):169-74 & Original/experimental & Renal & Nefrectomía & Técnica \\
\hline Valero G et al. & 2006 & 30 (3): $301-304$ & Original & Renal & Nefrectomía & Tratamiento \\
\hline Vega Vega A et al. & 2005 & 29(3):277-80 & Original & Cáncer adrenal & Adrenalectomía & Tratamiento \\
\hline \multirow[t]{2}{*}{ Villavicencio Marvrich $\mathrm{H}$} & 2006 & $30(1): 1-12$ & Original & Varias & Varias & Robótica \\
\hline & 2005 & 29(10):919-921 & Editorial & Varias & Varias & Robótica \\
\hline
\end{tabular}

*Los autores aparecen por orden alfabético y de publicación más reciente a la más antigua.

técnica. De esta forma, en los primeros capítulos del monográfico se tratan los temas sobre modelos de experimentación animal, simuladores artesanales, cursos especializados, programas hospitalarios de formación y ética y laparoscopia.
Todos ellos pasos necesarios dentro de la sistemática de aprendizaje. En una segunda parte se ha realizado una revisión de las técnicas de cirugía oncológica por laparoscopia y sus complicaciones. 
En la Tabla 1 se recogen las referencias de todos los artículos publicados en Actas Urológicas Españolas sobre laparoscopia. La primera referencia data de 1985, cuando la laparoscopia únicamente tenía un papel diagnóstico. La última referencia es de abril del 2006. La tabla sólo recoge aquellos artículos publicados en Actas Urológicas Españolas, por lo que es evidente que han quedado fuera de ella otros grupos españoles implicados en laparoscopia. Incluso puede que en la revisión realizada se haya pasado por alto alguna referencia, por lo que pido disculpas de antemano. Tampoco aparecen los autores de este monográfico, exponentes del vigor actual de la laparoscopia. Con esta editorial quiero rendir un pequeño homenaje a todos los urólogos que tuvieron la imaginación de apostar por el abordaje laparoscópico y que, además, decidieron publicarlo en ..... Actas.

Dr. J.L. Ruiz Cerdá

Director de Actas Urológicas Españolas 